\title{
An additional deep-water mass in Drake Passage as revealed by ${ }^{3} \mathrm{He}$ data
}

\author{
Roland Well $^{\mathrm{a}, 1}$, Wolfgang Roether ${ }^{\mathrm{a}, *}$, David P. Stevens ${ }^{\mathrm{b}}$ \\ ${ }^{a}$ Institut für Umweltphysik, Universität Bremen, FB 1, Postfach 330440, Bremen D-28344, Germany \\ ${ }^{\mathrm{b}}$ School of Mathematics, University of East Anglia, Norwich, UK
}

Received 8 February 2002; received in revised form 2 December 2002; accepted 14 February 2003

\begin{abstract}
We present ${ }^{3} \mathrm{He}$ data from a repeat section across Drake Passage, from three sections off the South American continent in the Pacific, at $28^{\circ} \mathrm{S}, 35^{\circ} \mathrm{S}$, and $43^{\circ} \mathrm{S}$, and from three sections in the Atlantic, eastward of the Malvinas, close to $35^{\circ} \mathrm{W}$, and near the Greenwich Meridian. In Drake Passage, a distinct high- ${ }^{3} \mathrm{He}$ signal is observed that is centered just above the boundary of the Lower and the Upper Circumpolar Deep Water (LCDW, UCDW), and is concentrated towards the northern continental slope. ${ }^{3} \mathrm{He}$ concentrations in the Antarctic Circumpolar Current (ACC) upstream of Drake Passage (World Ocean Circulation Experiment section P19 at $88^{\circ} \mathrm{W}$ ) are markedly lower than those found in Drake Passage, and a regional source of primordial helium in the path of the ACC that might cause the high- ${ }^{3} \mathrm{He}$ feature can be ruled out. We explain the feature by addition of high $-{ }^{3} \mathrm{He}$ waters present at the $43^{\circ} \mathrm{S}$ Pacific section. This supports a previous, similar interpretation of a low-salinity anomaly in Drake Passage (Naveira Garabato et al., DeepSea Research I 49 (2002) 681), that is strongly related to the high $-{ }^{3} \mathrm{He}$ feature. Employing multiparameter water mass analysis (including ${ }^{3} \mathrm{He}$ as a parameter), we find that deep waters as met at the $43^{\circ} \mathrm{S}$ Pacific section, flowing south along the South American continental slope, contribute substantially to the ACC waters in Drake Passage (fractions exceed $50 \%$ locally). Lesser, but laterally more extended contributions are found east of the Malvinas, and still smaller ones are present at $35^{\circ} \mathrm{W}$ and at the Greenwich Meridian. Using velocity measurements from one of the two Drake Passage sections, we estimate the volume transport of these waters to be $7.0 \pm 1.2 \mathrm{~Sv}$, but the average transport may be somewhat lower as the other realization had a less pronounced signal. The enhanced ${ }^{3} \mathrm{He}$ signature in Drake Passage is essentially confined north of the Polar Front. Further downstream the signature crosses this front, to the extent that at $35^{\circ} \mathrm{W}$ the contributions south and north of it are of similar magnitude. At the same time, the ${ }^{3} \mathrm{He}$ levels north of the front are reduced due to a substantial admixture of low- ${ }^{3} \mathrm{He}$ North Atlantic Deep Water, such that ${ }^{3} \mathrm{He}$ becomes highest south of the front. The flow of Southeast Pacific deep slope waters entering the ACC constitutes the predominant exit pathway of the primordial helium released in the deep Pacific, and represents a considerable fraction of the deep water return flow from the Pacific into the ACC. Therefore and also because the density range of the added deep slope waters is intermediate between those of UCDW and LCDW, they must be considered a distinct water mass.
\end{abstract}

(C) 2003 Elsevier Ltd. All rights reserved.

Keywords: Interocean exchange; Deep ocean; Antarctic Circumpolar Current; Water mass analysis; Primordial helium; ${ }^{3} \mathrm{He}$

\footnotetext{
*Corresponding author. Fax: +49-421-218-7018.

E-mail address: wroether@physik.uni-bremen.de (W. Roether).

${ }^{1}$ Now at T-Systems, Stuttgart, Germany.
} 


\section{Introduction}

The dominant deep-water masses in Drake Passage, according to common notion, are the Upper and the Lower Circumpolar Deep Water (UCDW, LCDW). They are among the principal water masses on a global scale, in part by their sheer volume, but also because LCDW is the main precursor of Antarctic Bottom Water (Orsi et al., 1993). LCDW and UCDW are said to fill the entire cross section of the passage below the Antarctic Intermediate Water horizon, except for a limited occurrence of Southeast Pacific Deep Water and Weddell Sea Deep Water within the lowest strata in southern Drake Passage (Sievers and Nowlin, 1984). LCDW is characterized by a salinity maximum, induced by the addition of North Atlantic Deep Water (NADW) which joins the Antarctic Circumpolar Current (ACC) in the Atlantic sector, while UCDW features an oxygen minimum, which is ascribed to addition of lowoxygen deep waters from the Indian and Pacific Oceans. Their boundary coincides closely with a density of $\sigma_{2}=37.0 \mathrm{~kg} \mathrm{~m}^{-3}$ (Orsi et al., 1995). However, recent work has demonstrated the presence of waters in Drake Passage within the CDW depth range that deviate from the general $T / S$ relationship in CDW towards low salinity (Naveira Garabato et al., 2002). The feature was found to be centered close to the UCDW/LCDW boundary and to be concentrated towards the northern continental slope. The authors argue that these waters are contributed by deep southward flow along the western margin of the South American continent, as is implied in maps of (adjusted) dynamic height by Reid (1986, 1997); the flow is apparent in the data of Tsuchiya and Talley (1998) at $54^{\circ} \mathrm{S}$ as a deep core with consistent hydrographic properties. The waters of such a core are hereinafter termed Southeast Pacific Deep Slope Water (SPDSW). The flow should be part of the general deep return flow from the Pacific into the ACC, which Schmitz (1996) derives as 17 Sverdrup (Sv; $1 \mathrm{~Sv}=10^{6} \mathrm{~m}^{3} \mathrm{~s}^{-1}$ ), and Tsimplis et al. (1998) report as $12 \mathrm{~Sv}$ (CDW component only). Neither of these analyses notes any substantial southward flow close to the South American continental slope, disregarding Reid (1986).
The schematic flow scheme of Schmitz (1996), in fact, suggests the return flow rejoins the ACC near $90^{\circ} \mathrm{W}$. On the other hand, Key et al. (1996) note a deep ${ }^{14} \mathrm{C}$ minimum adjoining the South American slope that they interpret as indicative of a deep southward return flow, and such flow has indeed been recorded by a moored deep current meter (Shaffer et al., 1995). In the same area, Shaffer et al. (2000) observed a slight decrease in oxygen between a depth of 1800 and $2900 \mathrm{~m}$ in 1995 relative to the SCORPIO values in 1967 (Warren, 1973). Taking these observations in combination with the work of Reid (1997), they propose that an eastern deep return flow exists that might have increased in strength after 1967.

Following the entry of the ACC into the Atlantic sector, CDW is altered considerably by admixture of lower-salinity waters from the south and higher-salinity NADW from the north in a complex pattern, as assessed in detail by Naveira Garabato et al. (2002). Such admixtures tend to mask the presence of SPDSW, although the authors were able to identify a contribution over the Falkland Plateau near $49.5^{\circ} \mathrm{W}$. The surprising fact that SPDSW went unnoticed in previous accounts of the Drake Passage hydrography is presumably due to emphasis being placed on property sections rather than on the $T / S$ relationship (Sievers and Nowlin, 1984). A similar oversight happened in the analysis of Roether et al. (1993) of data from World Ocean Circulation Experiment (WOCE) Drake Passage section A21 carried out in 1990 . However, ${ }^{3} \mathrm{He}$ data from this section were found to display an excess over ${ }^{3} \mathrm{He}$ concentrations found elsewhere in the ACC and the Southern Ocean (Rüth, 1998), and it has turned out that the excess was distributed across the section quite like the previously mentioned low-salinity feature. In order to enable evaluation of this ${ }^{3} \mathrm{He}$ signature, the Bremen tracer group has since carried out a dedicated collection of helium isotope data. In this contribution, we present the completed data set, and use it to analyze the high- ${ }^{3} \mathrm{He} / \mathrm{low}$-salinity feature in some detail, expanding the assessment of Naveira Garabato et al. (2002). Our particular goals are to confirm SPDSW as the source, to estimate the fractional contribution of the high- ${ }^{3} \mathrm{He} / \mathrm{low}$-salinity SPDSW 
waters to the ACC waters in Drake Passage, and to assess the fate of the waters as the anomalies fade away downstream due to mixing. The main tool in this is multiparameter water mass analysis, using ${ }^{3} \mathrm{He}$ as an additional parameter. Even though the ${ }^{3} \mathrm{He}$ data have a more limited spatial resolution, this tracer is useful because it has favourable boundary conditions inasmuch as SPDSW distinctly exceeds all other contributing water masses in ${ }^{3} \mathrm{He}$ concentration (see below).

The utility of ${ }^{3} \mathrm{He}$ as an ocean tracer rests on inner-ocean helium sources which raise the ${ }^{3} \mathrm{He}$ levels over those due to the solubility nearequilibria with atmospheric helium that prevail in the ocean mixed layer. In the waters treated below, such excess is almost exclusively due to ${ }^{3} \mathrm{He}$-rich helium added at spreading mid-ocean ridges (MOR) and tectonically active hot spots (so-called primordial helium). ${ }^{3} \mathrm{He}$ arising from the decay of bomb tritium is negligibly small in comparison, and that due to natural tritium represents a minor background (Roether et al., 1998), which, because it is also rather homogeneous, is irrelevant for the analysis below. The source strength of primordial helium varies greatly with location. Particularly prominent sources are located on the East Pacific Rise (EPR), rendering the deep and bottom waters of the Pacific the highest in ${ }^{3} \mathrm{He}$ globally (Lupton, 1998; Well et al., 2001). The ${ }^{3} \mathrm{He}$ excess due to these and other ocean bottom sources gets mixed through the ocean volume and is eventually lost by exchange with the atmosphere at the ocean surface. As a result, ${ }^{3} \mathrm{He}$ levels in the deep Pacific decline markedly southward into the ACC. ${ }^{3} \mathrm{He}$ sources in the Atlantic are small in comparison, so that in the Atlantic sector the situation is reversed and the ACC acts as a net source of ${ }^{3} \mathrm{He}$ (Rüth et al., 2000). Naturally, ${ }^{3} \mathrm{He}$ levels in the ACC are intermediate between those of the Pacific and the Atlantic, and, according to previous observations (Jamous et al., 1992; Lupton, 1998), they appear to cover only a rather limited range.

\section{Data and methods}

We use helium isotope data from the hydrographic sections shown in Fig. 1 (cruises are listed in Table 1). Data collection in the SONNE and in the two JAMES CLARK ROSS (JCR) sections was specifically meant to assist in the interpretation of the ${ }^{3} \mathrm{He}$ signature on the 1990 Drake Passage section of METEOR; JCR 40 also included a near-repeat of this section. JCR 40 likewise partly repeated the JCR 10 section south of South Georgia, but this repeat is not addressed. The METEOR, SONNE, and JCR helium samples were collected in clamped copper containers and measured at the helium isotope facility at the University of Bremen (Roether et al., 1998). Only

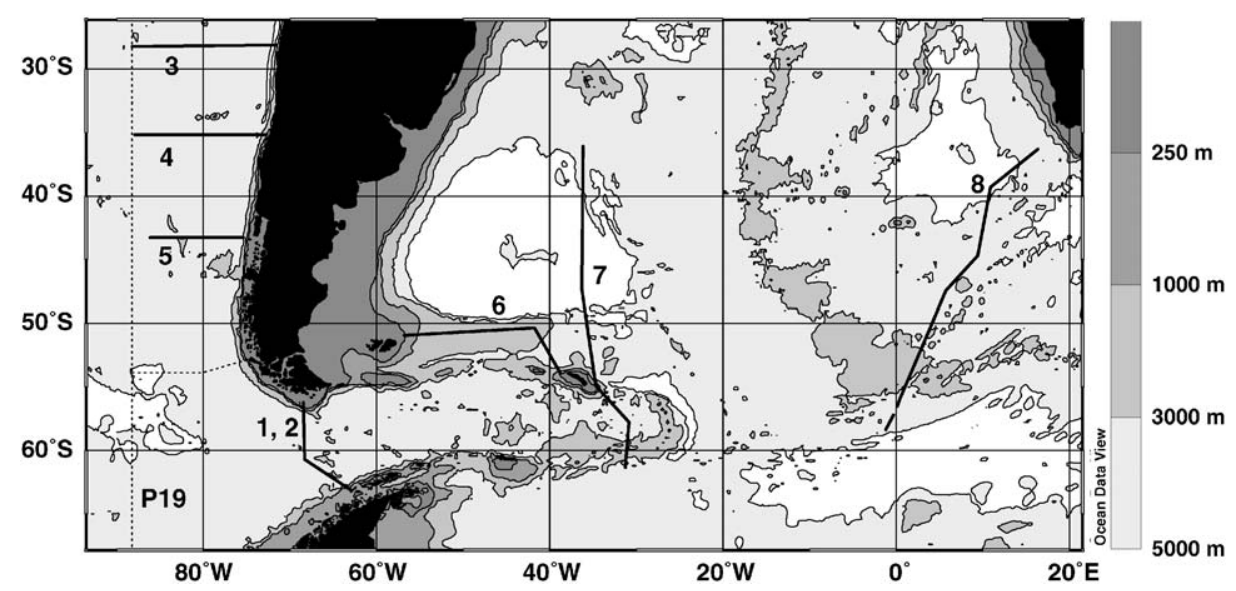

Fig. 1. Map of hydrographic sections $1-8$ used in the present work (solid lines; for cruise listing see Table 1 ) and of WOCE P19, $88^{\circ} \mathrm{W}$ (dotted line, including the part near $54^{\circ} \mathrm{S}$ towards the South American continent). Depth isolines are 250, 1000, 3000, and 5000 m. 
Table 1

The data-providing cruises

\begin{tabular}{|c|c|c|c|}
\hline Cruise, acronym & $\begin{array}{l}\text { Line no. } \\
\text { (see Fig. 1) }\end{array}$ & Date (month/year) & PI (hydrography, nutrients) \\
\hline $\begin{array}{l}\text { METEOR } 11 / 5 \text { WOCE } A 21, \text { WOCE } \\
A 12^{\mathrm{a}}\end{array}$ & 1,8 & $01 / 1990-03 / 1990$ & $\begin{array}{l}\text { E. Fahrbach, G. Rohardt, Alfred } \\
\text { Wegener Institut, Bremerhaven, } \\
\text { Germany } \\
\text { J. Swift, F. Delahoyde, ODF Scripps, } \\
\text { USA. }\end{array}$ \\
\hline $\begin{array}{l}\text { JAMES CLARK ROSS } 40 \\
\text { ALBATROSS }\end{array}$ & 2,6 & 03/1999-04/1999 & $\begin{array}{l}\text { K. Heywood, D. Stevens University } \\
\text { of East Anglia, Norwich, UK. }\end{array}$ \\
\hline $\begin{array}{l}\text { JAMES CLARK ROSS } 10 W O C E \\
A 23^{\mathrm{a}}\end{array}$ & 7 & $03 / 1995-05 / 1995$ & $\begin{array}{l}\text { K. Heywood University of East } \\
\text { Anglia, Norwich, UK. }\end{array}$ \\
\hline SONNE $102^{\mathrm{b}}$ & $3-5$ & $05 / 1995-06 / 1995$ & $\begin{array}{l}\text { G. Shaffer, Danish Center for Earth } \\
\text { System Science (DCESS), University } \\
\text { of Copenhagen, Denmark }\end{array}$ \\
\hline
\end{tabular}

${ }^{a}$ Data obtained from WHPO.

${ }^{\mathrm{b}}$ Hydrographic data obtained from G. Shaffer.

the data for the METEOR Drake Passage (WOCE section A21) and JCR 10 (WOCE section A23) sections have been reported previously (Rüth, 1998). We additionally use data from the Pacific WOCE section P19 $\left(88^{\circ} \mathrm{W}\right)$ (Lupton, 1998). Helium isotope sections are presented in the common delta notation, $\delta^{3} \mathrm{He}$, which denotes the fractional difference of a measured ${ }^{3} \mathrm{He} /{ }^{4} \mathrm{He}$ ratio from that of atmospheric helium $\left(\left({ }^{3} \mathrm{He} /{ }^{4} \mathrm{He}\right)_{\mathrm{atm}}=1.384 \times 10^{-6}\right.$; Clarke et al., 1976). The 1-Sigma precision of the $\delta^{3} \mathrm{He}$ data is generally $\pm 0.2 \% \quad\left(\delta^{3} \mathrm{He}\right.$ is a robust parameter such that offsets between different data sets can be ignored in the present context). The ocean-atmosphere solubility equilibrium which as mentioned governs the $\delta^{3} \mathrm{He}$ values in the mixed layer, corresponds to approximately $\delta^{3} \mathrm{He}=-1.7 \%$ (Benson and Krause, 1980).

We furthermore use hydrographic and nutrient/ oxygen data from these cruises (Table 1) to obtain water densities and for performing water mass analysis. Intercalibrated data were used for the METEOR, JCR 10, and P19 data (Gouretski and Jancke, 2001; Johnson et al., 2001). These intercalibrations do not address a comparison between Pacific and Atlantic data. We make the assumption that data biases between the two oceans are small, because of the large number of more or less independent data sets on which the intercalibra- tions for each of the two oceans are based. For the other sections no intercalibration is available. The JCR 40 nutrient and oxygen data were adjusted to the METEOR data, and the SONNE data to those of P19 (deep data only; the $28^{\circ} \mathrm{S}$ and $35^{\circ} \mathrm{S}$ SONNE sections meet $\mathrm{P} 19$ at $88^{\circ} \mathrm{W}$ ). We augmented the data for the $43^{\circ} \mathrm{S}$ SONNE section using data from the 1967 Scorpio section at the same latitude (Warren, 1973), which we similarly adjusted to P19 using stations close to the crossing of the two sections. The nutrient data partly do not meet WOCE precision standards (WCRP, 1988). As a consequence, the phosphate data of JCR 40 and the nitrate data of JCR 10 north of the Polar Front (PF) are omitted.

For water mass analysis, we use Optimum Multiparameter Analysis (OMP) (Mackas et al., 1987; Tomczak and Large, 1989; Hinrichsen and Tomczak, 1993) in the form given by Fleischmann (1997). In the OMP approach, one employs $n$ parameters to determine, under a non-negativity constraint, the relative contributions of up to $n$ water masses, or rather, so-called water types. The latter term means loci in parameter space for which all waters in question can be adequately represented as linear combinations, so that more than one water type may be needed to represent a given water mass. As mass conservation provides an additional constraint, one deals with an 
overdetermined system, so that for any observed parameter vector, the OMP yields the most probable composition (in a least squares sense) with respect to these water types. Suitable water types and parameter vectors for them (including error margins reflecting the uncertainty within which a parameter value can be specified), are chosen on the basis of plots of all other parameters versus salinity. The parameters considered useful (i.e., regarded as sufficiently conservative) are temperature (temperature always means potential temperature), salinity, silicate, the nutrientoxygen combinations $\mathrm{NO}\left(=9 \mathrm{NO}_{3}+\mathrm{O}_{2}\right)$ and $\mathrm{PO}$ $\left(=175 \mathrm{PO}_{4}+\mathrm{O}_{2}\right)$ (Broecker, 1974; Broecker et al., 1985), and ${ }^{3} \mathrm{He}$. Due to a near-redundancy of NO and $\mathrm{PO}$ and the previously mentioned quality limitations of the nutrient data, we use only one of these combinations at a time. The possible number of water types is thus limited to five, and the handling of this limit is a critical issue. One approximation applied in this context is that we primarily account for waters of similar density, considering that quasi-isopycnal transport should dominate over diapycnal transport. The OMP residual provides a measure of compatibility of the chosen water types and the observations. Each parameter is normalized by the mean uncertainty of the water-type values for that parameter, and the residual is formulated such that values exceeding unity indicate a problem. Whenever this limit is significantly exceeded, we dismiss the result. Another matter is the uncertainty margins of the water-type compositions for which the residual is deemed acceptable. These uncertainties are derived by determining the compositions many times, varying the chosen parameter values for the various water types within their respective uncertainty margins in a random manner. ${ }^{3} \mathrm{He}$ turns out to be a highly significant parameter, but it is only available for part of the parameter vectors. For the Drake Passage sections (only), we maximize spatial resolution by adding a separate analysis restricted to four parameters (i.e., omitting ${ }^{3} \mathrm{He}$ ), and recalibrating the water-type compositions obtained using the subset of fiveparameter-OMP compositions.

Considering that $\delta^{3} \mathrm{He}$, representing a normalized isotopic ratio, displays a certain non-linearity when waters of different $\delta^{3} \mathrm{He}$ mix, we use in the OMP the concentration of ${ }^{3} \mathrm{He}$ due to the innerocean sources ('non-atmospheric ${ }^{3} \mathrm{He},{ }^{3} \mathrm{H}_{\text {na }}$; in our case essentially primordial $\left.{ }^{3} \mathrm{He}\right)$, which, according to Roether et al. $(1998,2001)$, is given by

$$
\begin{aligned}
{ }^{3} \mathrm{He}_{\mathrm{na}}= & \left\{\left[\left(\delta^{3} \mathrm{He}-\delta^{3} \mathrm{He}_{0}\right) /\left(1+\delta^{3} \mathrm{He}_{0}\right)\right](1+\Delta \mathrm{He})\right. \\
& +\Delta(\mathrm{He} / \mathrm{Ne})(1+\Delta \mathrm{Ne})+\text { correct }{ }^{3} \mathrm{He}_{0} .
\end{aligned}
$$

A zero subscript indicates solubility-equilibrium values relative to atmospheric concentrations under standard pressure, $\Delta X$ stands for $\left(X-X_{0}\right) /$ $X_{0}$ with, ' $X$ ' representing the measured $\mathrm{He}$ and $\mathrm{Ne}$ concentration or $\mathrm{He} / \mathrm{Ne}$ concentration ratio, and 'correct' represents a small and rather constant offset $(\leqslant 0.5 \%$ for data of the Bremen facility if solubility values of Weiss (1971) are used) that accounts for differences between $\mathrm{He}$ and $\mathrm{Ne}$ in instrument calibration and in the degree of equilibration in the mixed layer of the contributing source areas. As the OMP deals with concentration differences, the offset is irrelevant. The leading term in (1) is the dominant one, but the second term, which represents the non-atmospheric $\mathrm{He}$, introduces additional uncertainty which is partly of a systematic nature. Careful intercalibration between the Bremen data from the different cruises (e.g., Rüth, 1998) ensures that offsets between the cruises are small. The estimated overall uncertainty (1-Sigma equivalent) for the data set used in the OMP (data precision plus remaining biases between cruises) is $\pm 0.4 \%$ of ${ }^{3} \mathrm{He}_{0}$. For $\mathrm{P} 19$, the helium isotope data were adjusted to the Bremen scale and estimated $\mathrm{Ne}$ values were used since $\mathrm{Ne}$ measurements do not exist. This approach is outlined elsewhere (Well et al., 2001), and should introduce little extra uncertainty $(\leqslant 0.2 \%)$.

\section{3. ${ }^{3} \mathrm{He}$ distributions}

The $\delta^{3} \mathrm{He}$ distributions along the sections of Fig. 1 are presented in Fig. 2. Isolines of potential density referenced to $2000 \mathrm{dbar}\left(\sigma_{2}, \mathrm{~kg} \mathrm{~m}^{-3}\right.$, the units are omitted hereafter) are included to assist in comparisons between the sections. The feature 


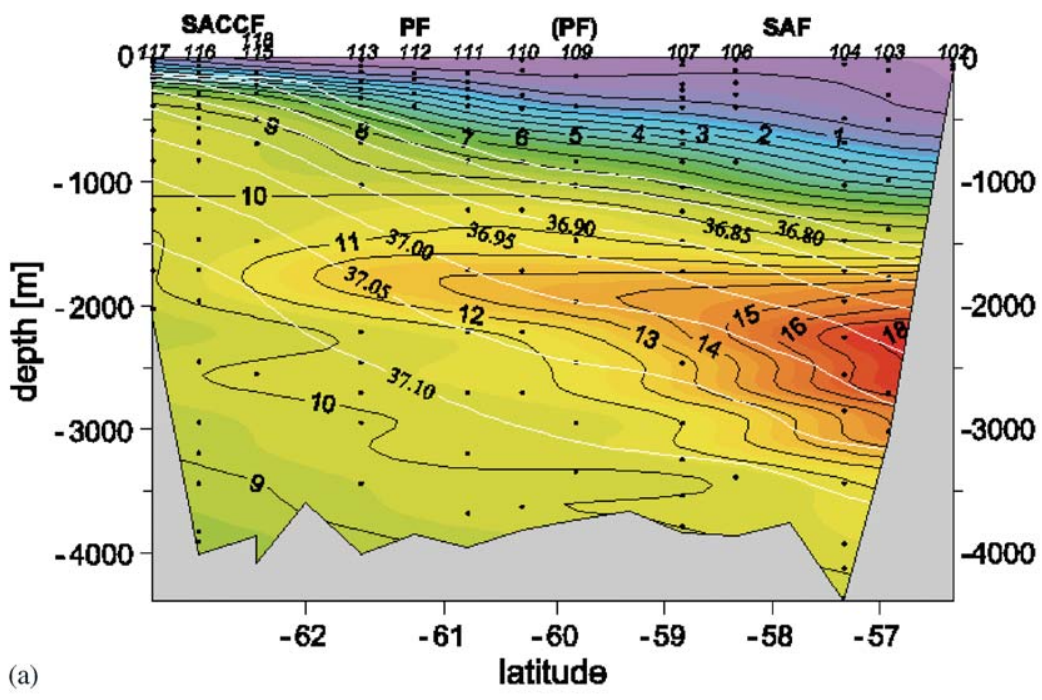

(a)

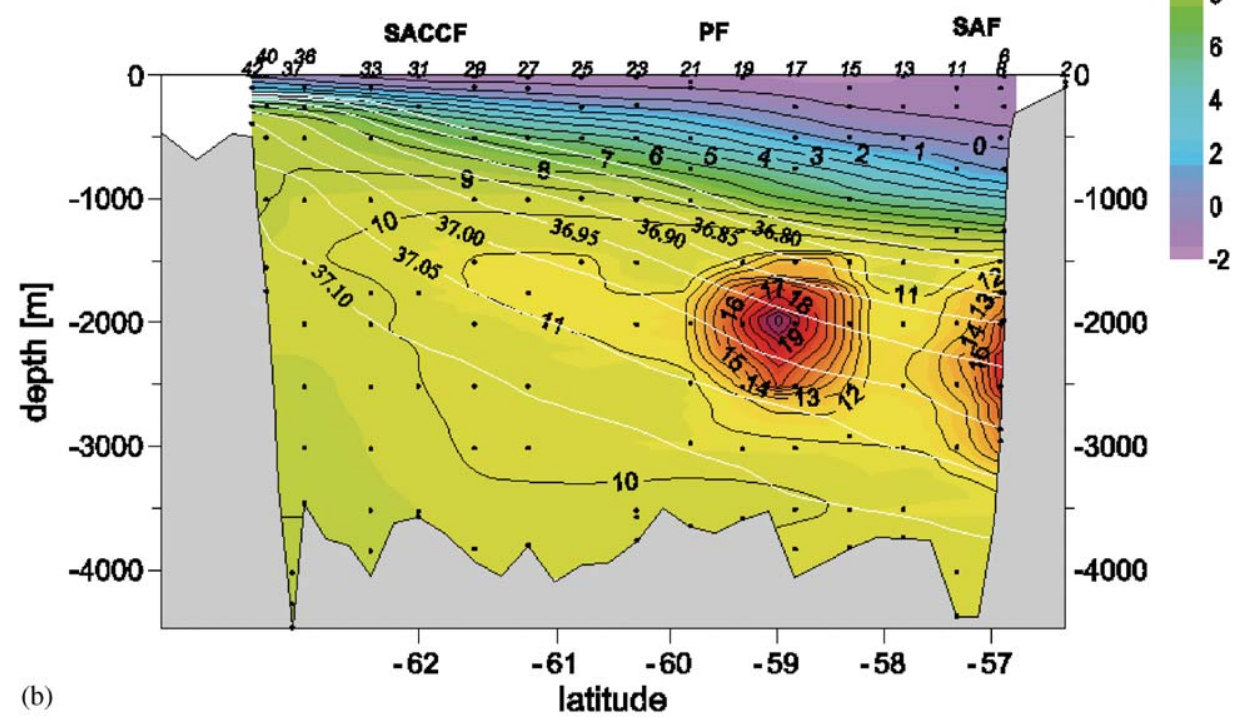

Fig. 2. $\delta^{3} \mathrm{He}$ isolines (\%) for sections 1-8 of Fig. 1, data points are indicated by dots and station numbers are given along the top of each section. Only the depth ranges of interest are shown. $\delta^{3} \mathrm{He}$ color scales are given in the margins (note different color scales), numerical values are given aligned with the $\delta^{3} \mathrm{He}$ isolines. $\sigma_{2}$ isolines are shown as white lines with values $\left(\mathrm{kg} \mathrm{m}^{-3}\right)$ aligned. Numbers close to data points in $(\mathrm{f}-\mathrm{h})$ are the deduced SPDSW fractions, see Section 4. Approximate front positions according to the definitions of Orsi et al. (1995) are indicated (SAF-Subantactic Front, PF-Polar Front, SACCF-Southern ACC Front). (a) Section 1 (METEOR M11/5, 1990; WOCE section A21) across Drake Passage; north is to the right. For secondary PF (in parentheses) see text. (b) Section 2 (JAMES CLARK ROSS 40, 1999) across Drake Passage. (c) Section 3 (SONNE 102, 1995), southeast Pacific $28^{\circ} \mathrm{S}$ off the South American continent. Distance and depth scales are identical for (c-e). (d) Section 4, same as (c), but 35 ${ }^{\circ}$ S. (e) Section 5, same as (c), but $43^{\circ}$ S. (f) Section 6 (JAMES CLARK ROSS 40, 1999), Falkland Plateau-Georgia Basin. Station numbers up to 140 are in the Georgia Basin, and the break between essentially zonal and meridional direction (Fig. 1) occurs at Sta. 142; the horizontal scale is distance preserving. West is to the left, so that the SAF appears to the left of the PF, in contrast to $(\mathrm{g})$ and (h). The numbers next to the $\delta^{3} \mathrm{He}$ data points represent fractional SPDSW contributions ( $\%$; see Section 4), to be distinguished from the $\delta^{3} \mathrm{He}$ values shown at the $\delta^{3} \mathrm{He}$ isolines. Distance and depth scales are identical for $(\mathrm{f}-\mathrm{h})$. (g) Section 7 (JAMES CLARK ROSS 10, 1995; WOCE section A23), Scotia Sea-Argentine Basin meridional section, ca. $61-38^{\circ} \mathrm{S}, 32-37^{\circ} \mathrm{W}$; fractional SPDSW contributions as indicated in (f). North is to the right. (h) Section 8 (METEOR M11/5, 1990; WOCE section A12), Greenwich Meridian-Cape Basin meridional section, about $58.5-36^{\circ} \mathrm{S}$; fractional SPDSW contributions as indicated in (f). 

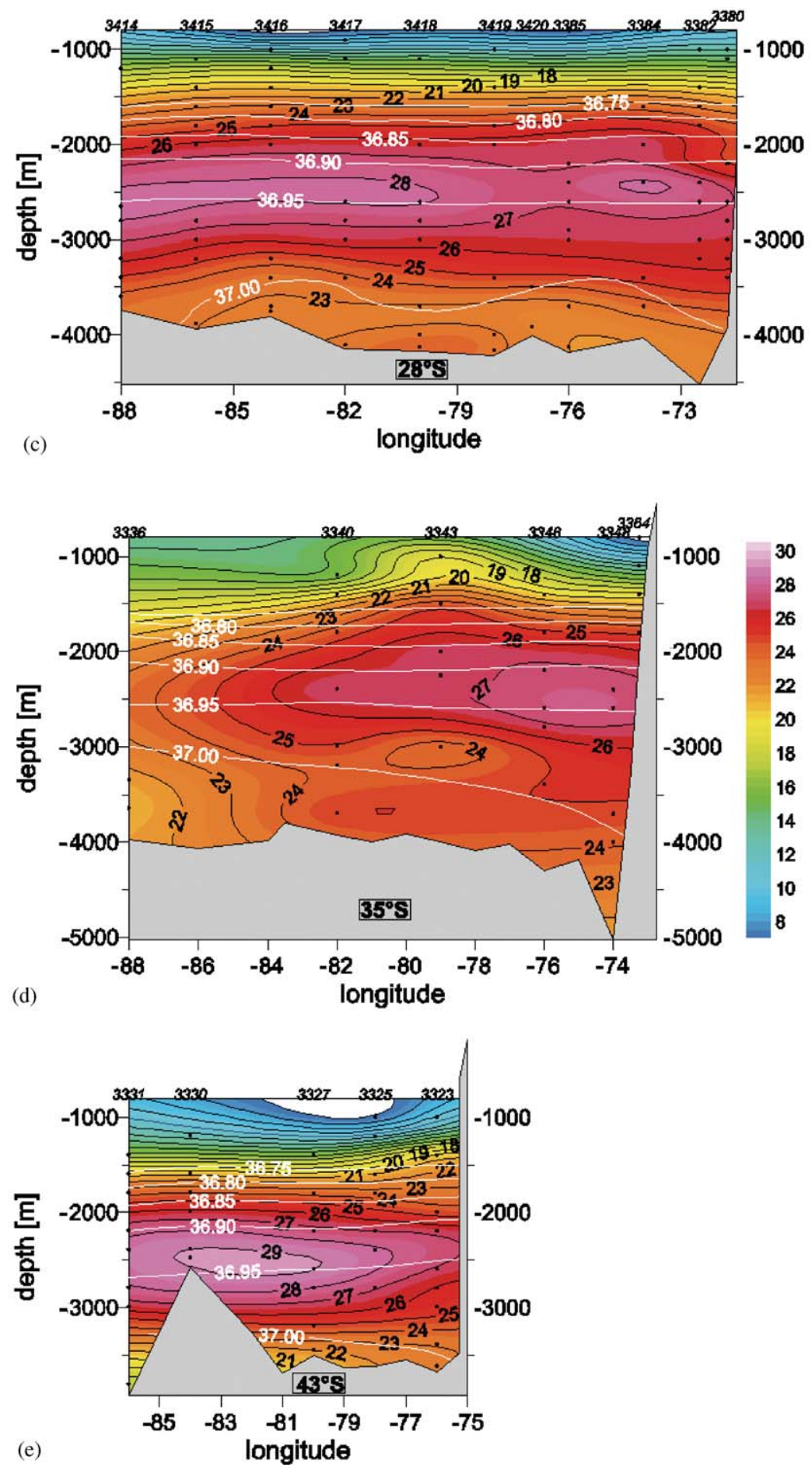

Fig. 2 (continued). 

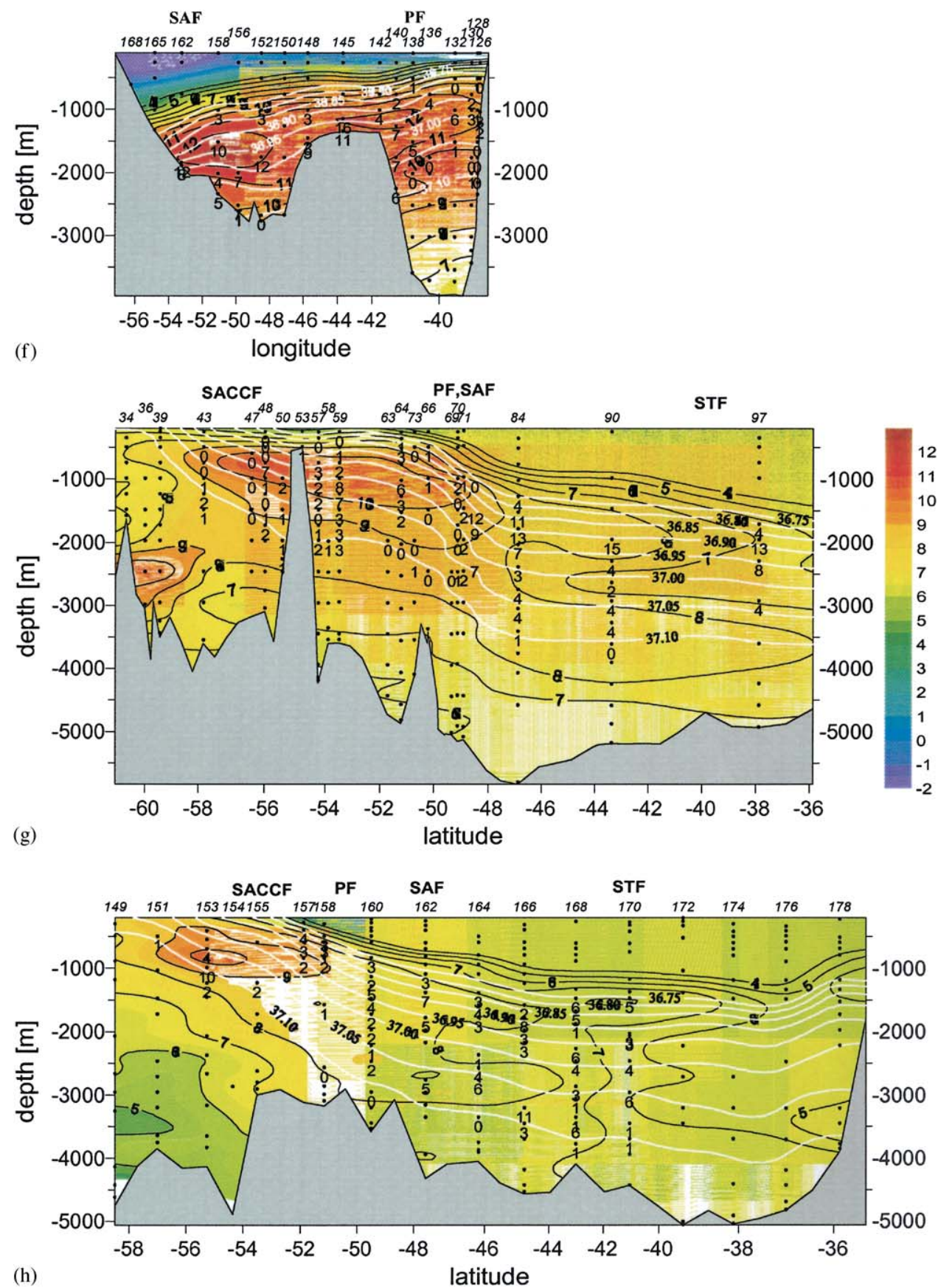

Fig. 2 (continued).

of central interest is the ${ }^{3} \mathrm{He}$ maxima at mid-depth in the two realizations of the Drake Passage section (Figs. 2a and b). In both realizations, the maxima are centered near $\sigma_{2}=36.95$, i.e., just above the boundary separating UCDW and LDCW at 37.0 (Orsi et al., 1995), and they are 
concentrated towards the northern continental slope. Maximum $\delta^{3} \mathrm{He}$ values are approximately $20 \%$, while overall, the ${ }^{3} \mathrm{He}$ signature in the JCR section appears to be a little stronger. Enhanced concentrations show up mostly north of the PF, more strictly so in the METEOR section (Fig. 2a), for which the PF is also situated farther south (the METEOR section displayed a secondary PF at about $60^{\circ} \mathrm{S}$ (Roether et al., 1993), relative to which the southward extension of the feature is similar to that in the JCR section). The JCR section (Fig. 2b) reveals a second, even stronger $\delta^{3} \mathrm{He}$ maximum between the PF and the Subantarctic Front (SAF). While some of the structures in Figs. 2a and b may be due to the limited spatial resolution of the data points and their contouring, the noted differences between the two realizations are clearly significant, revealing the transient nature of the high- ${ }^{3} \mathrm{He}$ signature at Drake Passage.

Comparatively higher $\delta^{3} \mathrm{He}$ values, up to about $29 \%$, are found at the sections off the South American continent in the southeast Pacific (Figs. 2c-e), where ${ }^{3} \mathrm{He}$ maxima are also present centered on densities close to those in Drake Passage. Within the somewhat limited resolution of the data, the maximum at $28^{\circ} \mathrm{S}$ is rather extended horizontally with a slight decrease towards the continental slope. It seems to be more centered towards the slope at $35^{\circ} \mathrm{S}$, and to be again somewhat off-slope and more horizontally confined at $43^{\circ} \mathrm{S}$. We suggest that the $28^{\circ} \mathrm{S}$ section is governed by ${ }^{3} \mathrm{He}$ advected from the EPR (see below), which becomes more concentrated towards the South American continental slope as it flows up to the $35^{\circ} \mathrm{S}$ section. The slightly higher and more off-slope $\delta^{3} \mathrm{He}$ peak in the $43^{\circ} \mathrm{S}$ section is probably due to ${ }^{3} \mathrm{He}$ addition at the Chile Rise which crosses this section (the peak in topography at $84^{\circ} \mathrm{W}$ ), as this ridge is an active MOR and thus an expected source of ${ }^{3} \mathrm{He}$ (DeMets et al., 1990).

The next section downstream of Drake Passage, i.e., the Falkland Plateau-Georgia Basin section in the southwest Atlantic (Fig. 2f), likewise displays a ${ }^{3} \mathrm{He}$ maximum layer centered at the expected density, which shoals towards the east and south. The maximum $\delta^{3} \mathrm{He}$ values are distinctly lower than in Drake Passage (maximum $<13 \%$ ), and the layer is now rather more homogeneous laterally.
There is no longer a ${ }^{3} \mathrm{He}$ maximum adjoining the slope. $\delta^{3} \mathrm{He}$ maxima are apparent to the east of the SAF (between Stas. 152-162), and adjoining the PF (between Stas. 138- and 145), coinciding with preferred transport routes across the section (Naveira Garabato et al., 2002). Although the ACC south of the PF is only partly shown, the enhanced- ${ }^{3} \mathrm{He}$ signature evidently is no longer confined to north of this front, as was the case in Drake Passage. One notices the rather $10{ }^{-}{ }^{3} \mathrm{He}$ levels above and below the maximum layer, compared to the Pacific and Drake Passage sections.

The Scotia Sea-Argentine Basin section (Fig. 2g), which crosses the ACC only moderately further east, offers a cross section right through the ACC. The ACC is depicted as an enhanced- ${ }^{3} \mathrm{He}$ feature, but with values reduced further compared to the previous section $\left(\delta^{3} \mathrm{He}<11 \%\right)$. The noted trend of increasing occurrence of elevated- ${ }^{3} \mathrm{He}$ waters south of the PF continues, to the extent that the highest ${ }^{3} \mathrm{He}$ values are now found south of this front, in complete contrast to the situation at Drake Passage. It appears that the feature is now centered at a slightly higher density, i.e., close to $\sigma_{2}=37.0$. The ${ }^{3} \mathrm{He}$ minimum north of the PF near this density, i.e., close to the classical UCDWLCDW boundary, indicates intrusion of NADW which is low in ${ }^{3} \mathrm{He}$ (Rüth et al., 2000). The Weddell Sea-derived near-bottom waters also show up as a lower- ${ }^{3} \mathrm{He}$ region. The isolated high- ${ }^{3} \mathrm{He}$ core at the southern end of the section near $2500 \mathrm{~m}$ depth is a local feature, arising from a ${ }^{3} \mathrm{He}$ source in that area (Barker et al., 1991); it shows up similarly in the corresponding JCR 40 ${ }^{3} \mathrm{He}$ data (not shown). This core is irrelevant in the context of the present work as it is located at a much higher density than the waters under consideration. The Greenwich Meridian-Cape Basin section (Fig. 2h) qualitatively looks much the same, with the enhanced- ${ }^{3} \mathrm{He}$ feature again being centered close to $\sigma_{2}=37.0$ and with NADW intruding southward. Maximum ${ }^{3} \mathrm{He}$ values are not reduced much further $\left(\delta^{3} \mathrm{He} \leqslant 10.5 \%\right)$, but the cross-sectional area for which $\delta^{3} \mathrm{He}$ exceeds $9 \%$ is distinctly smaller. At this section, low- ${ }^{3} \mathrm{He}$ Weddell Sea-derived waters are prominent south of $54^{\circ} \mathrm{S}$ below about $3000 \mathrm{~m}$. 
As for the origin of the high- ${ }^{3} \mathrm{He}$ feature observed at the ACC crossings, a comparison with the next available ${ }^{3} \mathrm{He}$ section across the ACC upstream of Drake Passage, i.e., WOCE P19 at $88^{\circ} \mathrm{W}$ (Lupton, 1998; Plate I), reveals that the high- ${ }^{3} \mathrm{He}$ signature in Drake Passage (Figs. 2a and b) cannot be due to advection by the ACC. At that section, $\delta^{3} \mathrm{He}$ is rather more homogeneous and distinctly lower than at corresponding locations in Drake Passage. From the south, $\delta^{3} \mathrm{He}$ is nearly uniform at $11 \%$ up to the SAF (located close to $\left.59^{\circ} \mathrm{S}\right)$. From here on, the values increase northward; high values as observed in Drake Passage are only approached at about $53^{\circ} \mathrm{S}$. An alternative to advection with the ACC from $88^{\circ} \mathrm{W}$ would be addition of primordial helium along the ACC path between the $88^{\circ} \mathrm{W}$ and Drake Passage sections. However, there are no geologically active regions that might raise the ${ }^{3} \mathrm{He}$ levels in this area (DeMets et al., 1990). It is therefore clear that the high- ${ }^{3} \mathrm{He}$ signature in Drake Passage must have a different source, and the remaining possibility is addition of ${ }^{3} \mathrm{He}$-rich Pacific waters between $88^{\circ} \mathrm{W}$ and Drake Passage. The $\mathrm{P} 19 \delta^{3} \mathrm{He}$ values steadily increase northward of $53^{\circ} \mathrm{S}$, but at $43^{\circ} \mathrm{S}$ and $35^{\circ} \mathrm{S}$, they are lower than the maximum values on the SONNE 102 sections (Figs. 2d and e), which confirms the existence of ${ }^{3} \mathrm{He}$ maxima near the slope at these sections. At $28^{\circ} \mathrm{S}$, on the other hand, P19 shows a meridionally restricted core of ${ }^{3} \mathrm{He}$ values similar to those found at the SONNE section (Fig. 2c). This agreement suggests that there is advection from the EPR sources (see Introduction) near that latitude.

Fig. 3a shows the $T / S$ relationship for the 1990 Drake Passage section. Between about $1.2^{\circ} \mathrm{C}$ and $2.1^{\circ} \mathrm{C}$, the $T / S$ data appears to scatter. However, data from individual stations tend to follow one of two paths as noted for the JCR 40 section by Naveira Garabato et al. (2002), who assigned the low-salinity variety to addition of what we call SPDSW. The ${ }^{3} \mathrm{He}_{\mathrm{na}} /$ salinity relationships for both Drake Passage sections are shown in Fig. 3b. This graph makes the high ${ }^{3} \mathrm{He}$ feature particularly evident, and also highlights the somewhat stronger ${ }^{3} \mathrm{He}$ signal on the JCR 40 section (cf. Figs. 2a and b). Both graphs of Fig. 3 include the water-type property values used for the OMP of these sections.
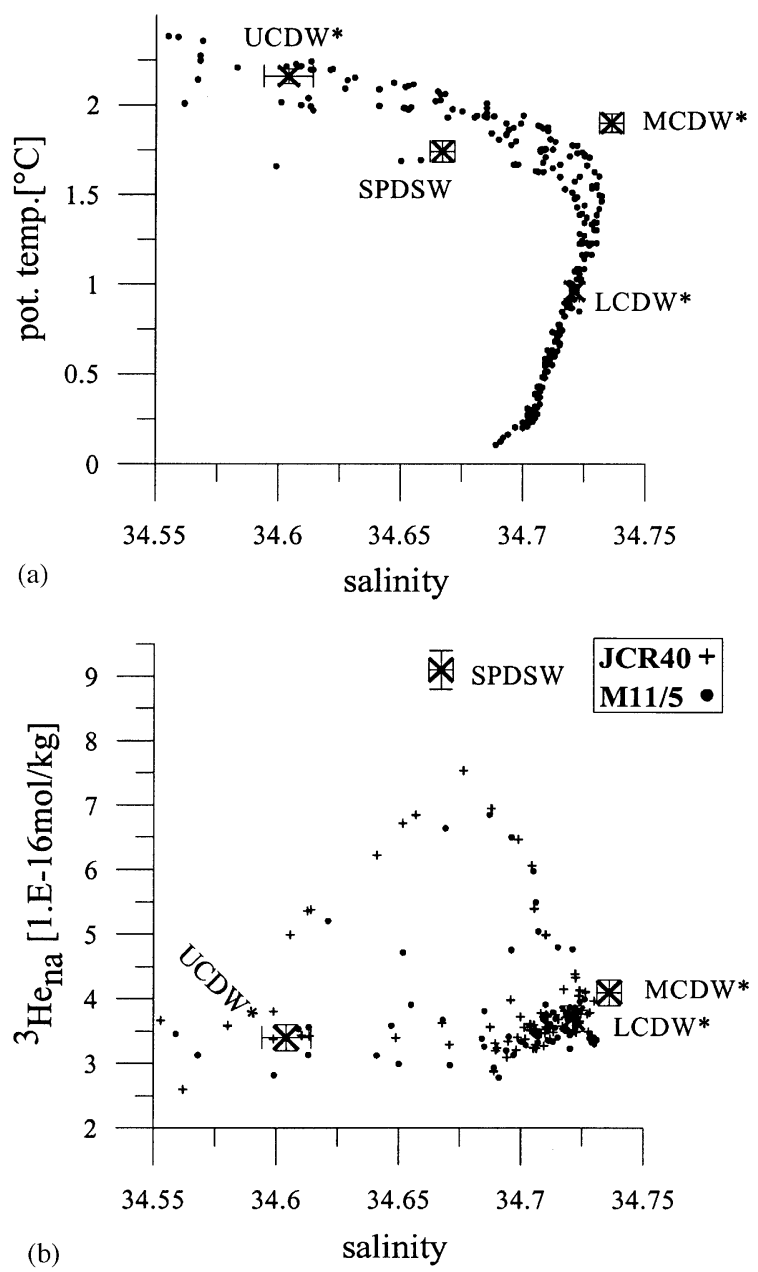

Fig. 3. Potential temperature-salinity diagram for the M11/5 (a) and ${ }^{3} \mathrm{He}$-salinity diagrams for the M11/5 (dots) and JRC 40 (crosses) Drake Passage sections (b) $\left({ }^{3} \mathrm{He}\right.$ as defined by Eq. (1), uncertainty about \pm 0.1 units). Also shown are the water types used in the OMP (Section 4).

\section{OMP-derived SPDSW fractions}

To analyze the water mass structure at Drake Passage, we make the assumption that the Drake Passage waters in a density range covering the high $-{ }^{3} \mathrm{He}$ feature are composed of ACC waters as observed at $88^{\circ} \mathrm{W}$, and of SPDSW. The required water-type parameter vectors were chosen on the basis of the property-property plots of Fig. 4 (Pacific $88^{\circ} \mathrm{W} / \mathrm{P} 19$ section, $59-62.3^{\circ} \mathrm{S}$, and the $43^{\circ} \mathrm{S}$ combined SONNE/SCORPIO section). 

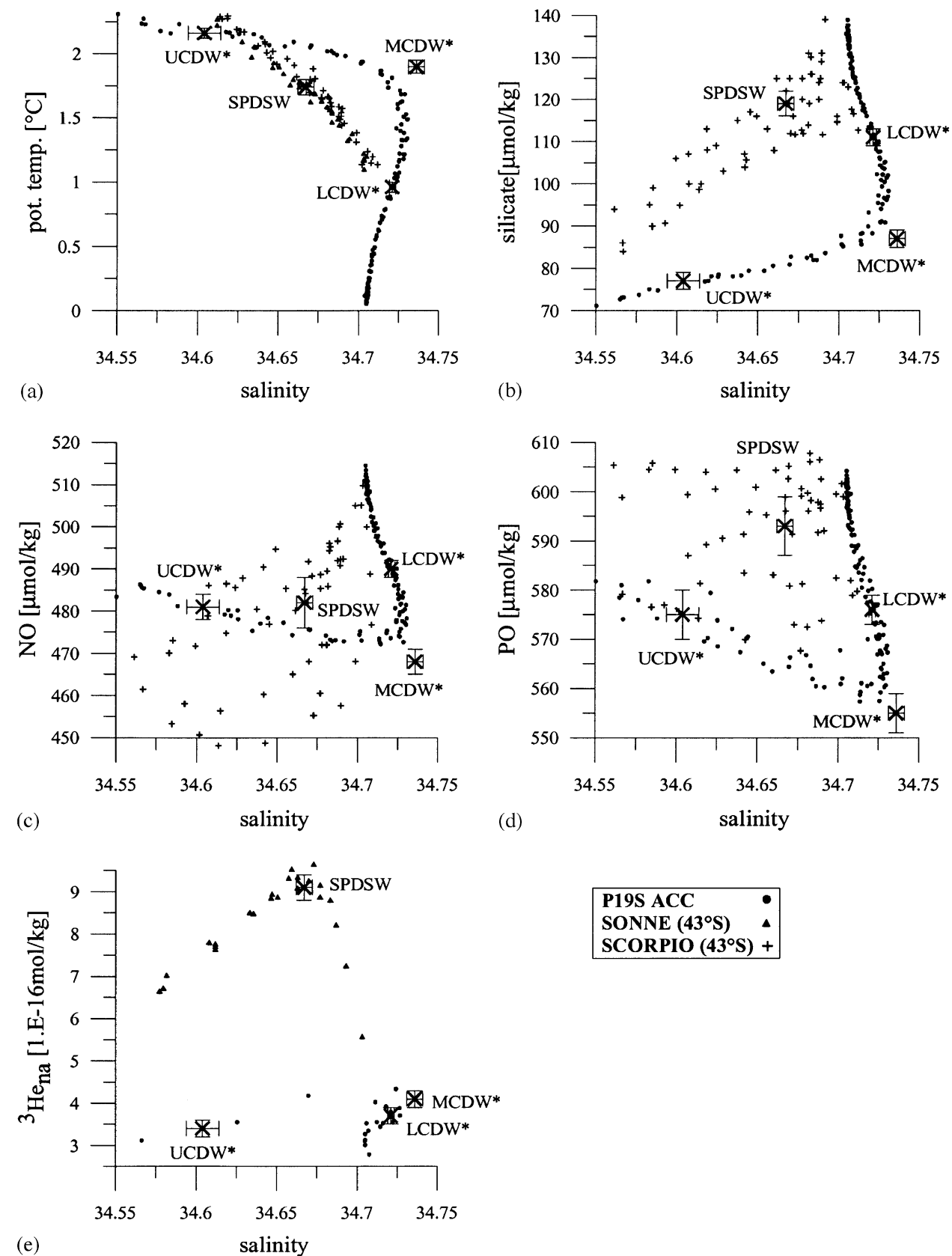

Fig. 4. Parameter plots versus salinity for the P19 section $\left(88^{\circ} \mathrm{W}\right)$ and for the combined SONNE $102 /$ SCORPIO $43^{\circ} \mathrm{S}$ sections (see Fig. 1), potential temperature (a), silicate (b), NO (c), PO (d), and ${ }^{3} \mathrm{He}(\mathrm{e})$. The water types used to characterize the water mass composition in Drake Passage (UCDW*, MCDW*, LCDW*, SPDSW) are indicated (for parameter values see Table 2).

Fig. 4a shows the $T / S$ relationship. The curvature of the P19 values in the range of interest $(\sim 1.2-$ $\left.2.1^{\circ} \mathrm{C}\right)$ means that a minimum of three water types are needed to characterize the $88^{\circ} \mathrm{W}$ waters. The loci actually chosen are marked as $\mathrm{UCDW}^{*}$, $\mathrm{MCDW}^{*}$, and $\mathrm{LCDW}^{*}$. The water types are 
starred, in order to distinguish them from the water masses UCDW and LDCW commonly referred to; for $\mathrm{MCDW}^{*}$ ('middle' CDW) there is no corresponding established water mass (however see Conclusions). The water type to characterize SPDSW at the $43^{\circ} \mathrm{S}$ section was taken to correspond to the ${ }^{3} \mathrm{He}$ maximum in Fig. 2e, averaged over $700 \mathrm{~m}$ in depth, and over a horizontal scale of the deep slope current taken from the work of Reid (1997) (his Fig. 5h; approximately $78-88^{\circ} \mathrm{W}$ ). The following graphs (Figs. 4b-e) show the corresponding plots for silicate, $\mathrm{NO}, \mathrm{PO}$, and ${ }^{3} \mathrm{He}_{\mathrm{na}}$ versus salinity with the same water types marked. Evidently, the chosen water types are compatible with all hydrographic parameters in question. It is particularly gratifying that, as Fig. 4e shows, SPDSW stands out in ${ }^{3} \mathrm{He}$ content compared to the P19 water types, which among themselves differ little in ${ }^{3} \mathrm{He}$. The parameter values for the four water types (including uncertainties based on the data spreads in Fig. 4) are listed in Table 2. The water types are also shown in Fig. 3, demonstrating that they represent a consistent choice for the Drake Passage sections.

The OMP-derived SPDSW fractions shown in Figs. 5 and 2 have been obtained using only one of the two parameters $\mathrm{NO}$ and $\mathrm{PO}$ at a time (see Table 3). This was done for the sake of consistency considering that for JCR 40 (Sections 2 and 6) and also for JCR 10 north of the PF (Section 7) only one of these parameters was deemed useful (see Section 2). To convince ourselves that this restriction did not introduce any significant bias, we ran an additional OMP for the METEOR Drake Passage section using both parameters. The SPDSW fractions obtained agreed with those of the regular run (i.e., using NO only) within the uncertainties, and furthermore, the uncertainties were about the same. This result is taken as evidence that adding the second of the parameters in question yields little additional information. Uncertainties in the SPDSW fractions, estimated as outlined in Section 2, are mentioned below, but in view of the small numbers of data points involved, the values are not too well constrained.

Fig. 5 shows the fractional SPDSW contributions for the two Drake Passage sections. A sizeable number of the data points represent recalibrated four-parameter compositions as explained above (Section 2; calibration factor for M11/5 (JCR 40) $1.23 \pm 0.03(1.17 \pm 0.02)$ on the basis of 6 (10) data pairs of a sufficiently large SPDSW contribution, the error is the 1-Sigma error of the mean); consistency of this approach is indicated by agreement of the calibration factors within errors. The uncertainties in composition are about $\pm 2 \%$ (absolute) for the five-parameter compositions, and $\pm 5-7 \%$ for the four-parameter compositions, so that a reasonable mean error is $\pm 5 \%$ (absolute), with a small extra effect of the recalibration uncertainty. The apparent data scatter appears to be rather larger, which we interpret as indicating the distributions to be highly structured. As it was felt that contouring was unlikely to be objective, the graphs also include the numerical SPDSW values. The values exceed $50 \%$ locally, meaning that at its maxima SPDSW is a major contributor. Both sections show cores adjoining the northern continental slope. A second maximum between the SAF and the PF is barely noticeable in the M11/5 section (Fig. 5a), but very evident in the JCR 40 section (Fig. 5b) where this maximum displays the largest values of all (up to $70 \%$ ). South of the PF, SPDSW contributions are insignificant in the METEOR section (values for depths $<1000 \mathrm{~m}$ are regarded invalid, one reason being the possible presence of tritiugenic ${ }^{3} \mathrm{He}$ ) and very limited in the JCR section (see also the note on PF positions in Section 3).

Downstream of Drake Passage, the situation is more difficult to handle as now several additional water masses exert an influence (Naveira Garabato et al., 2002). To restrict the number of water types involved, we allow for only two varieties of southern, low-salinity waters (one deep and one shallow, the latter being chosen differently for the waters north and south of the PF), and for one northern, high-salinity NADW-type water mass. Even this restriction raises the number of water types to seven, while the OMP can only handle five at a time. To cope with this limit, we split the water column vertically at $\sigma_{2}=36.95$, omitting the two densest water types when above this density and the two shallowest ones when below it. The density at which the split is made was chosen to minimize 


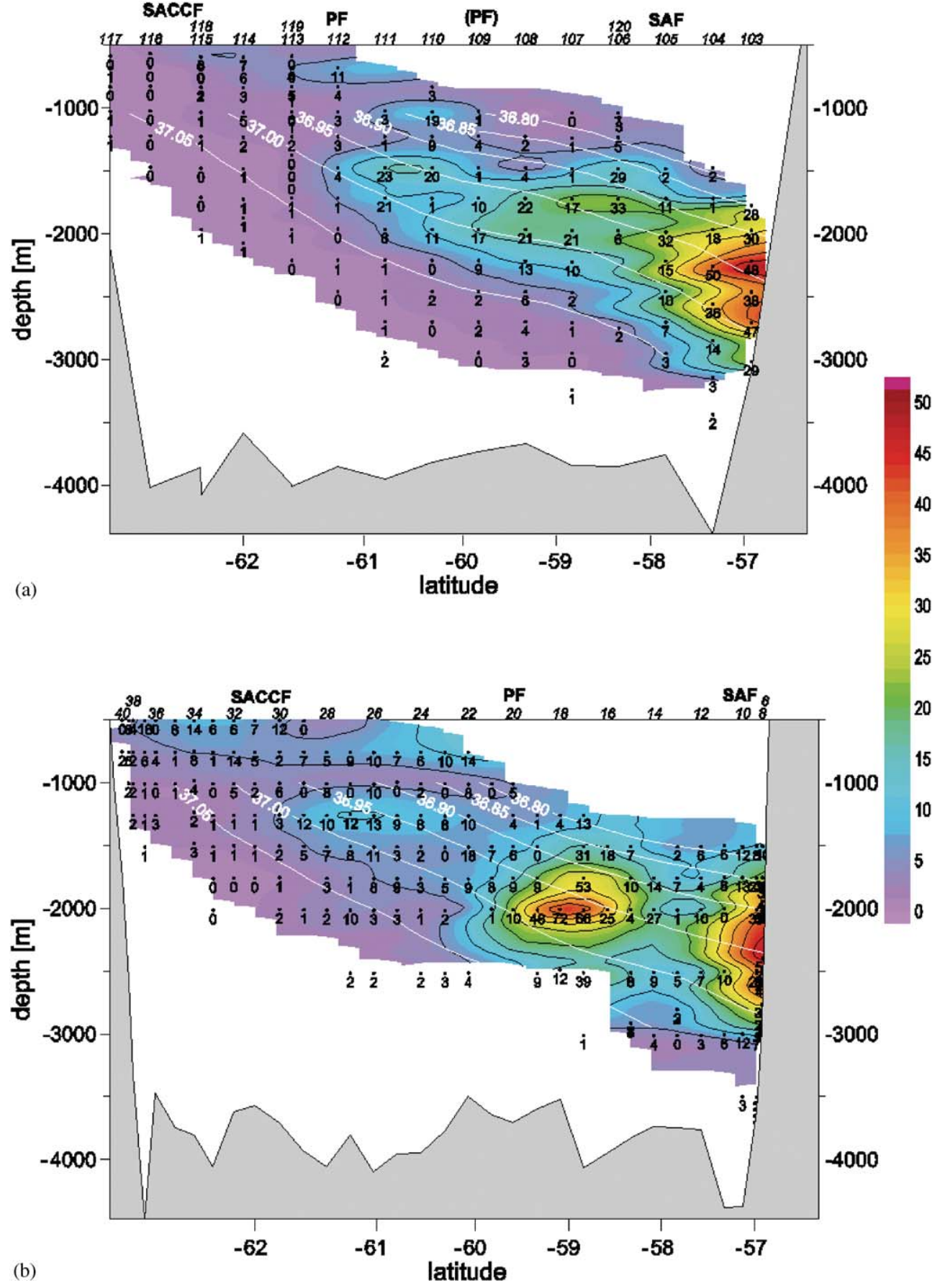

Fig. 5. Isolines of SPDSW contribution (\%) in the Drake Passage sections of M11/5 (a) and JCR 40 (b). The contributions are also given numerically (numbers next to the corresponding ${ }^{3} \mathrm{He}$ data points). North is to the right. $\sigma_{2}$ lines as in Fig. 2. 
Table 2

Parameter vectors of the water types employed in the OMP for the Drake Passage section, see Figs. 3 and 4, and text

\begin{tabular}{lllllll}
\hline Water type & $\begin{array}{l}\text { Pot. temp. } \\
\left({ }^{\circ} \mathrm{C}\right)\end{array}$ & Salinity & $\begin{array}{l}\text { Silicate } \\
\left.(\mu \mathrm{mol} \mathrm{kg})^{-1}\right)\end{array}$ & $\begin{array}{l}\mathrm{NO} \\
\left(\mu \mathrm{mol} \mathrm{kg}^{-1}\right)\end{array}$ & $\begin{array}{l}\mathrm{PO} \\
\left(\mu \mathrm{mol} \mathrm{kg}^{-1}\right)\end{array}$ & $\begin{array}{l}{ }^{3} \mathrm{He}_{\mathrm{na}} \\
\left(10^{-16} \mathrm{~mol} \mathrm{~kg}^{-1}\right)\end{array}$ \\
\hline $\mathrm{UCDW}^{*}$ & $2.16(0.04)$ & $34.604(0.010)$ & $77(2)$ & $481(3)$ & $575(5)$ & $3.4(0.2)$ \\
$\mathrm{MCDW}^{*}$ & $1.90(0.05)$ & $34.736(0.005)$ & $87(2)$ & $468(3)$ & $555(4)$ & $4.1(0.2)$ \\
LCDW $^{*}$ & $0.96(0.04)$ & $34.721(0.002)$ & $111(2)$ & $490(2)$ & $576(3)$ & $3.7(0.2)$ \\
SPDSW & $1.74(0.06)$ & $34.667(0.005)$ & $119(3)$ & $482(6)$ & $593(6)$ & $9.1(0.3)$ \\
\hline
\end{tabular}

Numbers in parentheses are uncertainties accounting for the scatter of the data on which the respective water type parameters are based (1-Sigma equivalent); PO is only used for part of the $35^{\circ} \mathrm{W}$ section, see Table 3 .

Table 3

Parameter vectors of the additional water types employed in the OMP for the sections downstream of Drake Passage (numbers in parentheses are uncertainties accounting for the scatter of the data on which the respective water type parameters are based (1-Sigma equivalent)), and locations from which the parameter values originate

\begin{tabular}{lllclll}
\hline $\begin{array}{l}\text { Water } \\
\text { type \# }\end{array}$ & $\begin{array}{l}\text { Pot. temp. } \\
\left({ }^{\circ} \mathrm{C}\right)\end{array}$ & Salinity & $\begin{array}{l}\text { Silicate } \\
\left(\mu \mathrm{mol} \mathrm{kg} \mathrm{kg}^{-1}\right)\end{array}$ & $\begin{array}{l}\mathrm{NO} \\
\left(\mu \mathrm{mol} \mathrm{kg}{ }^{-1}\right)\end{array}$ & $\begin{array}{l}\mathrm{PO} \\
\left(\mu \mathrm{mol} \mathrm{kg}^{-1}\right)\end{array}$ & $\begin{array}{l}{ }^{3} \mathrm{He}_{\mathrm{na}} \\
\left(10^{-16} \mathrm{~mol} \mathrm{~kg}^{-1}\right)\end{array}$ \\
\hline $1^{\mathrm{a}}$ & $1.90(0.05)$ & $34.400(0.01)$ & $64(2)$ & $510(7)$ & - & $2.3(0.2)$ \\
2 & $2.42(0.12)$ & $34.150(0.015)$ & $29(3)$ & $537(5)$ & - & $0.7(0.3)$ \\
3 & $0.39(0.05)$ & $34.677(0.007)$ & $114(2)$ & $507(5)$ & - & $3.1(0.2)$ \\
$4^{\mathrm{b}}$ & $1.60(0.15)$ & $34.180(0.02)$ & $47(3)$ & $534(3)$ & - & $1.4(0.2)$ \\
5 & $3.70(0.2)$ & $34.160(0.01)$ & $16(2)$ & - & $592(9)$ & $0.2(0.1)$ \\
6 & $0.39(0.05)$ & $34.677(0.007)$ & $114(2)$ & $507(5)$ & - & $3.1(0.2)$ \\
7 & $2.56(0.06)$ & $34.920(0.007)$ & $37(2)$ & - & $486(3)$ & $1.6(0.2)$ \\
$8^{\text {c }}$ & $2.00(0.08)$ & $34.400(0.008)$ & $61(2)$ & $516(5)$ & - & $1.9(0.2)$ \\
9 & $2.50(0.10)$ & $34.520(0.02)$ & $62(3)$ & $493(4)$ & - & $2.8(0.2)$ \\
10 & $0.38(0.05)$ & $34.683(0.002)$ & $117(2)$ & $510(3)$ & - & $3.1(0.2)$ \\
11 & $2.11(0.05)$ & $34.850(0.007)$ & $55(2)$ & $457(5)$ & - & $2.4(0.2)$ \\
\hline
\end{tabular}

Missing values of NO or PO mean that the respective parameter was not used in the OMP.

${ }^{a}$ Falkland Plateau-Georgia Basin section: \#1: Shallower southern water south of PF $=$ JCR 40 station: $125-136$, at about $\sigma_{0}=27.5$; \#2: Shallower southern water north of PF $=$ JCR 40 station: 139-161, at about $\sigma_{0}=27.3$; \#3: Deeper southern water $=$ Warm Deep Water of JCR40 at South Scotia Ridge, at about $\sigma_{2}=37.1$ (neutral density $=28.00-28.26$, pot. temp. $=0.2-0.6^{\circ} \mathrm{C}$ ). Northern water contribution ignored.

${ }^{\mathrm{b}}$ Scotia Sea-Argentine Basin section: \#4: Shallower southern water south of PF at A23, about $49-51^{\circ} \mathrm{S}$, about $\sigma_{0}=27.4$; \#5: Shallower southern water north of $\mathrm{PF}=$ Antarctic Intermediate Water at A23, about $47-49^{\circ} \mathrm{S}$, at about $\sigma_{0}=27.2$; \#6: Deeper southern water $=\# 3 ; \# 7$ : Northern water $=\mathrm{NADW}$ at A23, 28-34 $\mathrm{S}$, at about $\sigma_{2}=37.0$.

${ }^{\mathrm{c}}$ Greenwich Meridian Section: \#8: Shallower southern water south of $\mathrm{PF}=\mathrm{M} 11 / 5$ stations: $157-159$, at about $\sigma_{0}=27.5$; \#9: Shallower southern water north of $\mathrm{PF}=\mathrm{M} 11 / 5$ stations: $160-170$, at about $\sigma_{0}=27.5$; \#10: Deeper southern water $=\mathrm{A} 12$ at North Weddell Ridge, at about $\sigma_{2}=37.1$ (neutral density $=28.00-28.26$, pot. temp. $=0.2-0.6^{\circ} \mathrm{C}$ ); \#11: Northern water $=\mathrm{NADW}$ in the Southeast Atlantic from cruises A13 $\left(33-40^{\circ} \mathrm{S}\right)$ and A14 $\left(33-37^{\circ} \mathrm{S}\right)$, at about $\sigma_{2}=37.0$.

the contributions of the omitted water types. We found that at this density the remaining contributions of the respectively omitted water types are at most $5 \%$, so that any bias in the results should remain small.

The water-type parameter vectors for the additional water masses are listed in Table 3, together with the locations from which the definitions were taken. One finds that the characteristics mostly represent stations close to the longitude of the section for which they are employed. The deep southern water masses are the same for the Falkland Plateau-Georgia Basin and Scotia SeaArgentine Basin sections, and for the former, a 
northern contribution was ignored. While the actual parameter vector definitions are to some extent arbitrary, we note that the various properties are rather well correlated among the water masses of Table 3 (e.g., salinity and ${ }^{3} \mathrm{He}$ for the southern water masses). This means that the actual definitions are not too critical. In fact, if one were to shift, hypothetically, one of the water types in all properties in true proportion, the OMP would only yield a different contribution of that water type but the SPDSW values as such would remain unchanged. A contouring of the SPDSW contributions obtained was deemed unfeasible. Therefore, the contributions are included in Figs. $2 \mathrm{f}-\mathrm{h}$ in the form of numerical values plotted next to the corresponding ${ }^{3} \mathrm{He}$ data points.

For the Falkland Plateau-Georgia Basin section (Fig. 2f), the uncertainties in the SPDSW contributions are typically $\pm 2 \%(1 \%)$ absolute above (below) $\sigma_{2}=37.05$. Contributions range up to $16 \%$. Highest values show up related to, but seemingly somewhat displaced downward from, the two ${ }^{3} \mathrm{He}$ maxima noted above. Vanishing values are found for $\delta^{3} \mathrm{He} \leqslant 9.5 \%$ both above and below the ${ }^{3} \mathrm{He}$ maximum layer. The average SPDSW contribution over the section between $\sigma_{2}=36.80$ and 37.1 is approximately $5 \%$. For the Scotia Sea-Argentine Basin section (Fig. 2g), the next section downstream, the SPDSW contributions are smaller, i.e., at most about $10 \%$, and the uncertainties are now $\pm 4-5 \%$ north of the PF, but still only $1 \%$ south of it. The SPDSW contributions north and south of the PF are seemingly of similar magnitude (although the rather low signalto-noise ratio in the northern part requires a caveat), which contrasts with the distinct northward decrease in $\delta^{3} \mathrm{He}$. The reduced $\delta^{3} \mathrm{He}$ values north of the PF can be ascribed to addition of low- ${ }^{3} \mathrm{He}$ NADW. For the Greenwich MeridianCape Basin section (Fig. 2h), the SPDSW contributions are no higher than about $8 \%$ (when averaged over several data points), while uncertainties are between $3 \%$ and $5 \%$ (the latter value holds upward of $\sigma_{2}=37.0$ north of the PF). In view of the unfavourable signal-to-noise ratio, the data have to be interpreted with caution, but one again notes similar SPDSW contributions north and south of the PF. Seemingly, the cross-sectional area covered by detectable SPDSW is relatively larger north of the PF, but this might be an artifact of scatter in the data values. There is prominent NADW influence in the north as with the section immediately upstream.

\section{Discussion}

Fig. 2 and the OMP reveal that the ACC receives a substantial addition of ${ }^{3} \mathrm{He}$-rich waters just upstream of Drake Passage, and that this produces a distinct ${ }^{3} \mathrm{He}$ signature, which is strong in Drake Passage and can still be recognized at the Greenwich Meridian. A basic assumption in the OMP is that the addition of the ${ }^{3} \mathrm{He}$-rich waters is due to a deep southward flow along the South American continental slope (i.e., to SPDSW). Noting that potential source waters must comply with both elevated ${ }^{3} \mathrm{He}$ and an 'anomalous' $T-S$ relationship (i.e., lower salinity; Fig. 3a), the assumption is defended as follows: (i) Waters south of $53^{\circ} \mathrm{S}$ along $\mathrm{P} 19\left(88^{\circ} \mathrm{W}\right)$ are out of the question, as ${ }^{3} \mathrm{He}$ is definitively too low (Section 3). (ii) Along the zonal part of $\mathrm{P} 19$ near $54^{\circ} \mathrm{S}$ between $88^{\circ} \mathrm{W}$ and the continental slope (Fig. 1; Tsuchiya and Talley, 1998), the required $T-S$ anomaly is only found between $80^{\circ} \mathrm{W}$ and the slope, but not further west. Despite missing ${ }^{3} \mathrm{He}$ data, this finding proves that at that latitude there is in fact a nearslope core of waters with the required properties. (iii) Further north along P19, the 'anomalous' $T-S$ relationship is approached near $45^{\circ} \mathrm{S}$, while ${ }^{3} \mathrm{He}$ levels match those nearer to the slope only at $28^{\circ} \mathrm{S}$, but remain below them at $35^{\circ} \mathrm{S}$ and $43^{\circ} \mathrm{S}$ (Section 3). We conclude that the source waters do form a near-slope core, and that this core extends northward to at least about $45^{\circ} \mathrm{S}$. From there on, trajectories of the waters in question may begin to diverge westward, turning away from the slope, although the existence of the ${ }^{3} \mathrm{He}$ peak along P19 at $28^{\circ} \mathrm{S}$ points to a concentration of zonally oriented trajectories near this latitude. It follows that our definition of SPDSW properties (i.e., those of near-slope waters at $43^{\circ} \mathrm{S}$ ) is justified. Of course, there may be modest contributions of waters following other trajectories. Such additions, however, would dilute the original SPDSW 
properties, so that in Drake Passage the fractional contributions of SPDSW with such waters included, would have to be higher than we have deduced.

Our notion is in agreement with Reid's (1997) concentrated deep southward flow along the South American continental slope, and his eastward deep flow close to $28^{\circ} \mathrm{S}$. Furthermore, the implied entry of the high $-{ }^{3} \mathrm{He}$ waters a short distance upstream of Drake Passage readily explains the transient and highly structured nature of the ${ }^{3} \mathrm{He}$ signature in Drake Passage, which contrasts with a far smoother structure at the next section downstream (see Figs. 2a and b versus 2f).

As well as decreasing downstream of Drake Passage, the enhanced $-{ }^{3} \mathrm{He}$ structure, which is predominantly confined to the north of the PF in Drake Passage, extends some way south of this front by the next section downstream (the Falkland Plateau-Georgia Basin section). It is very striking that at the $35^{\circ} \mathrm{W}$ and Greenwich Meridian sections, markedly lower $\delta^{3} \mathrm{He}$ values are found north of the PF than further west, such that the $\delta^{3} \mathrm{He}$ maximum is now found south of the front, in strong contrast to the Drake Passage sections. This largely isopycnal movement of the enhanced $-{ }^{3} \mathrm{He}$ waters southward across the PF is indicative of the eddy transfer process discussed in recent dynamical studies of the ACC (e.g., Ivchenko et al., 1996; Karsten et al., 2002), and also in an earlier analysis of hydrographic and tracer data (Roether et al., 1993). While in Drake Passage the enhanced- ${ }^{3} \mathrm{He}$ waters are centered close to $\sigma_{2}=36.95$, the center further downstream appears to move towards $\sigma_{2}=37.0$, coinciding with the UCDW-LCDW boundary.

The maximum $\delta^{3} \mathrm{He}$ values within the ACC between the SAF and the Southern ACC Front are about $11 \%$ at $88^{\circ} \mathrm{W}$ in the southeast Pacific, up to $20 \%$ in Drake Passage, and $10 \%$ at the Greenwich Meridian (Fig. 2). For the ACC deep waters in the Indian Ocean, Jamous et al. (1992) report 8-9\%, and Lupton's (1998) WOCE P16 section at $152^{\circ} \mathrm{W}$ shows approximately $9 \%$. It follows that the variation in $\delta^{3} \mathrm{He}$ along the ACC is distinctly larger in the Atlantic sector than over the remainder of the ACC path up to $88^{\circ} \mathrm{W}$. This is a surprising finding, considering that the Pacific is the pre-eminent source of primordial helium globally (see Introduction). Evidently, a big jump in $\delta^{3} \mathrm{He}$ occurs between $88^{\circ} \mathrm{W}$ and Drake Passage, which, according to our analysis, is due to addition of SPDSW. This finding implies that much of the ${ }^{3} \mathrm{He}$ transfer from the Pacific sources of primordial helium into the ACC occurs immediately upstream of Drake Passage via the SPDSW. On the other hand, the $\delta^{3} \mathrm{He}$ gradients across the ACC do reflect the dominance of the Pacific sector as a source of ${ }^{3} \mathrm{He}$, in that at $88^{\circ} \mathrm{W}{ }^{3} \mathrm{He}$ levels at the SAF increase northward, while they decrease northward at the Greenwich Meridian.

The OMP works well for the Drake Passage sections. However, at the ACC crossings further downstream, the situation becomes more difficult as more water masses contribute than can be accounted for by the OMP. This discrepancy requires certain simplifications (see Section 4), so that the results for these sections are somewhat more uncertain. We maintain, however, that a SPDSW contribution is significant up to the Greenwich Meridian. Inclusion of ${ }^{3} \mathrm{He}$ data in the OMP has turned out to be crucial, as they provide the clearest representation of SPDSW. It has to be pointed out that the ${ }^{3} \mathrm{He}$ value that we deduced for SPDSW might be on the low side, since the Chile Rise, being an active MOR as previously mentioned, might raise the ${ }^{3} \mathrm{He}$ levels just south (i.e., downstream) of the $43^{\circ} \mathrm{S}$ section from which our value is derived. The issue could have been settled by ${ }^{3} \mathrm{He}$ data for the $54^{\circ} \mathrm{S}$ part of WOCE section P19 (Tsuchiya and Talley, 1998), but unfortunately this parameter was not sampled for on that section. If there were indeed a significant increase, the five-parameter analysis for the Drake Passage sections would tend to overestimate the SPDSW contributions, since the OMP would request a rather high contribution of this water type in order to make up for an unrealistically low ${ }^{3} \mathrm{He}$ content. In fact, as mentioned, the five-parameter OMP values are about $20 \%$ higher than those for the four-parameter OMP. Although this might indicate a modest overestimation of the SPDSW values, we rely on the five-parameter OMP values, since this version yields distinctly more robust results. 
For Drake Passage, the OMP yields substantial SPDSW contributions over a considerable fraction of the passage, i.e., north of the PF, with maximum values exceeding $50 \%$ (Fig. 5). The contributions are aligned with the isopycnals, and the center isopycnal is close to $\sigma_{2}=36.95$. The SPDSW addition is thus centered just above the boundary separating UCDW and LCDW at $\sigma_{2}=$ 37.0 , in contrast to the common notion that deep waters exported from the Pacific into the ACC replenish the UCDW at large (Orsi et al., 1995). Downstream of Drake Passage, mixing reduces the contributions to less than approximately $15 \%$ at the Falkland Plateau-Georgia Basin section (Fig. 2f). Up to this section, mixing within the ACC waters should predominate, as the OMPderived contributions of the external water masses remain rather small; only at the very base of the SPDSW-bearing layer (at $\sigma_{2}=37.1$ ) does the contribution of the deeper southern water mass rise to $30 \%$. For the sections further downstream (Figs. 2g and h), the SPDSW contributions north and south of the PF appear to be rather similar, which is surprising considering that the $\delta^{3} \mathrm{He}$ values distinctly increase southward. The further reduction of the SPDSW fraction is now more moderate, and it is affected to a large degree by admixture of waters adjoining the ACC. This holds in particular north of the PF, where the OMP yields NADW contributions of up to $70 \%$. The employed definition of NADW is a regional one (Table 3), so that the contributions of NADW proper are less, but undoubtedly still prominent. The high NADW contribution downstream of the Falkland Plateau-Georgia Basin section is presumably related to the large northward excursion of the SAF in the SW Atlantic and the fact that the SAF and PF are close together at the Scotia SeaArgentine Basin section while further downstream these fronts diverge. It is plausible that the water composition at and downstream of the convergence of the fronts is different than that further west. The present results support a notion that much of the admixture of NADW to the ACC occurs in the SW Atlantic west of approximately $35^{\circ} \mathrm{W}$ (Arhan et al., 2002).

It is possible to estimate the volume transport of SPDSW through Drake Passage using the
OMP-derived fractions and velocity estimates. We use geostrophic velocity profiles from the JCR 40 Drake Passage section referenced, by performing a least-squares fit, to detided Lowered Acoustic Doppler Current Profiler (LADCP) profiles (see Heywood and Stevens (2002), Arhan et al. (2002) and Naveira Garabato et al. (in press) for further details of the data collection and methods). Uncertainties for the resulting reference velocities are $4 \mathrm{~cm} \mathrm{~s}^{-1}$. Unfortunately, a faulty LADCP was used for the first 10 stations of the section (those in the north of Drake Passage). For profiles derived from these stations, the velocities were referenced to no flow at the ocean floor with an increased uncertainty of $10 \mathrm{~cm} \mathrm{~s}^{-1}$. The volume transport of SPDSW through the JCR 40 Drake Passage section is $7.0 \pm 1.2 \mathrm{~Sv}$. The uncertainty in the transport is computed by applying random perturbations (based on the individual uncertainties) to the barotropic velocities and the SPDSW fractions and computing the standard deviation of a large number (10000) of realizations of the resulting transport. This assumes the velocity errors are perfectly correlated in the vertical and uncorrelated in the horizontal and that there is no correlation between errors in SPDSW fractions. For the JCR 40 section, there are two main cores of SPDSW (Fig. 5b). The core close to the northern continental slope transports $1.2 \pm 0.8 \mathrm{~Sv}$, whilst the second core between the SAF and PF transports $4.9 \pm 0.9 \mathrm{~Sv}$. In the case of the M11/5 section, a similar estimate cannot be made due to missing reference velocities. The fact, however, that on that section the SPDSW signal (Fig. 5a) was somewhat less pronounced, may mean that JCR 40 met a larger than average volume transport, so that the mean value may be lower, perhaps only about $5 \mathrm{~Sv}$. But even such a rate would amount to a considerable fraction of the deep water return flow out of the Pacific (Schmitz, 1996; Tsimplis et al., 1998), which means that SPDSW should be considered as a major export route from the Pacific into the ACC not only for the primordial helium but also for Pacific deep waters as a whole. We note furthermore our derived SPDSW flow in Drake Passage is compatible with deep flow along the South American slope according to Reid's (1997) maps of adjusted 
dynamic height (very approximately $3.5 \mathrm{~Sv}$; assumed width (vertical extent) $10^{\circ}$ longitude $(700 \mathrm{~m})$ at $43^{\circ} \mathrm{S}$; see Section 4$)$.

\section{Conclusions}

Our analysis shows that a deep southward flow along the continental slope of the west coast of South America represents the predominant exit pathway into the ACC of the ${ }^{3} \mathrm{He}$ that is being released by the Pacific primordial-helium sources. The flow is also a major exit pathway of Pacific deep waters in general, supporting Reid (1986, 1997). The waters carried, for which we propose the term SPDSW, are characterized by low salinity and oxygen and high nutrients (Naveira Garabato et al., 2002). The estimated volume transport of SPDSW through Drake Passage is $7.0 \pm 1.2 \mathrm{~Sv}$ for one of our sections. The other realization had a less pronounced SPDSW signal, so that the mean volume transport may be somewhat less. In either case, the volume flow of SPDSW into the ACC amounts to a considerable fraction of that of NADW (Schmitz, 1996). SPDSW is thus a significant contributor to the ACC, with densities intermediate between UCDW and LCDW, and it must therefore be considered a separate deep ACC water mass in addition to UCDW and LCDW. In Drake Passage, the fractional contributions of SPDSW reach up to more than $50 \%$ locally and are essentially confined to north of the PF. Further downstream in the ACC, the SPDSW fractions drop sharply, and from about $35^{\circ} \mathrm{W}$ onward the total appears to be divided roughly equally between the waters north and south of the PF. The contribution can be followed up to the Greenwich Meridian. Our analysis relies strongly on ${ }^{3} \mathrm{He}$ as a water mass parameter in the ACC and adjoining waters, which capacity of ${ }^{3} \mathrm{He}$ may find applications beyond that in the present work.

In Drake Passage, the SPDSW waters have their center slightly above the boundary of UCDW and LCDW, while further downstream the center coincides with the water mass boundary. This contradicts the common notion that deep water export from the Pacific feeds into the UCDW at large (Orsi et al., 1995). In fact, the density range of SPDSW is rather more similar to that of NADW (Fig. 2g; Naveira Garabato et al., 2002). This means that SPDSW joins NADW, with a significant contribution, in replenishing the CDW waters at mid-range, i.e., close to the apparent break in property-property diagrams within the CDW depth range (such as in Figs. 3 and 4 near the water type marked $\mathrm{MCDW}^{*}$ ). One should note, however, that the property anomalies of the two water masses relative to CDW are generally of opposite sign. An example is the negative salinity anomaly that SPDSW effects in Drake Passage (Fig. 3a), which becomes counteracted, and thus masked, by the addition of high-salinity NADW not far downstream in the ACC. It follows that property balances may underestimate the contribution of NADW waters to the ACC if the effect of SPDSW is ignored.

\section{Acknowledgements}

We are grateful to the masters and crew of the METEOR, SONNE, and JAMES CLARK ROSS cruises for their support and cooperation, to the various chief scientists for assistance at sea, and to numerous helpers at sea and in the laboratory (notably Martin Butzin and Wilfried Plep, Bremen). Gerd Frass carried out the helium isotope analyses at Bremen, and Christine Rüth and Uli Fleischmann performed much of the final helium isotope data editing. We thank Karen Heywood, Norwich, UK, and Gary Shaffer, Copenhagen, for arranging participation in their cruises, and Gary Shaffer also for providing the complementary SONNE data. John Lupton, Newport, Oregon, supplied the P19 helium isotope data in digital form. The METEOR cruise was funded by the Deutsche Forschungsgemeinschaft, and the Bremen participation in the SONNE and the JAMES CLARK ROSS cruises, and also most of the helium isotope work at Bremen, were supported by the Bundesminister für Bildung und Forschung (BMBF; both institutions at Bonn-Bad Godesberg, Germany) under Grants 03F0538A, 03F0050B, 03F0121A, and 03F0157A. R.W. acknowledges support by the Deutsche Forschungsgemeinschaft, and D.S. by UK Natural 
Environmental Research Council GR3/11654, for carrying out the present evaluation.

\section{References}

Arhan, M., Naveira Garabato, A.C., Heywood, K.J., Stevens, D.P., 2002. The overflow of Southern Ocean water at the Falkland Plateau. Journal of Physical Oceanography 32, 1914-1931.

Barker, P.F., Dalziel, I.D.W., Storey, B.C., 1991. Tectonic evolution of the Scotia Arc region. In: Tingley, R.J. (Ed.), Antarctic Geology. Oxford University Press: Oxford, pp. 215-248.

Benson, B.B., Krause, D., 1980. Isotopic fractionation of helium during solution: a probe for the liquid state. Journal of Solution Chemistry 9, 895-909.

Broecker, W.S., 1974. NO as a conservative water-mass tracer. Earth and Planetary Science Letters 23, 100-107.

Broecker, W.S., Takahashi, Ta., Takahashi, Ti., 1985. Sources and flow patterns of deep-ocean waters as deduced from potential temperature, salinity, and initial phosphate concentrations. Journal of Geophysical Research 90 (C4), 6925-6939.

Clarke, W.B., Jenkins, W.J., Top, Z., 1976. Determination of tritium by mass spectrometric measurement of ${ }^{3} \mathrm{He}$. International Journal of Applied Radiation and Isotopes 27, 515-522.

DeMets, C., Gordon, R.G., Argus, D.F., Stein, S., 1990. Current plate motions. Geophysical Journal International 101, 425-478.

Fleischmann, U., 1997. Optimierte Auswertung von Tracerdaten. Diploma Thesis, Universität Bremen, unpublished.

Gouretski, V.V., Jancke, K., 2001. Systematic errors as the cause of an apparent deep water property variability: global analysis of the WOCE and historical hydrographic data. Progress in Oceanography 48, 337-402.

Heywood, K.J., Stevens, D.P., 2002. ALBATROSS cruise report. UEA Cruise Report Series No. 6, UEA Publications, Norwich, UK, 61pp.

Hinrichsen, H.-H., Tomczak, M., 1993. Optimum multiparameter analysis of the water mass structure in the western North Atlantic ocean. Journal of Geophysical Research 98, 10155-10169.

Ivchenko, V.O., Richards, K.J., Stevens, D.P., 1996. The dynamics of the Antarctic Circumpolar Current. Journal of Physical Oceanography 26, 753-774.

Jamous, D., Memery, L., Andrié, C., Jean-Baptiste, P., Merlivat, L., 1992. The distribution of helium 3 in the deep western and southern Indian Ocean. Journal of Geophysical Research 97, 2243-2250.

Johnson, G.C., Robbins, P.E., Hufford, G.E., 2001. Systematic adjustments of hydrographic sections for internal consistency. Journal of Atmospheric and Oceanic Technology 18, 1234-1244.
Karsten, R., Jones, H., Marshall, J., 2002. The role of eddy transfer in setting the stratification and transport of a circumpolar current. Journal of Physical Oceanography 32, 39-54.

Key, R.M., Quay, P.D., Jones, G.L., McNichol, A.P., von Reden, K.F., Schneider, R.J., 1996. WOCE AMS radiocarbon I: Pacific Ocean results (P6, P16 and P17). Radiocarbon 38 (3), 425-518.

Lupton, J.E., 1998. Hydrothermal helium plumes in the Pacific Ocean. Journal of Geophysical Research 103, 15853-15868.

Mackas, D.L., Denman, K.L., Bennet, A.F., 1987. Least squares multiple tracer analysis of water mass composition. Journal of Geophysical Research 92, 2907-2918.

Naveira Garabato, A.C., Heywood, K.J., Stevens, D.P., 2002. Modification and pathways of Southern Ocean deep waters in the Scotia Sea. Deep-Sea Research I 49, 681-705.

Naveira Garabato, A.C., Heywood, K.J., Stevens, D.P. Water mass conversion, fluxes and mixing in the Scotia Sea diagnosed by an inverse model. Journal of Physical Oceanography, in press.

Orsi, A.H., Nowlin Jr., W.D., Whitworth III, T., 1993. On the circulation and stratification of the Weddell Gyre. Deep-Sea Research I 40, 169-203.

Orsi, A.H., Whitworth III, T., Nowlin Jr., W.D., 1995. On the meridional extent and fronts in the Antarctic Circumpolar Current. Deep-Sea Research I 42, 641-673.

Reid, J.L., 1986. On the total geostropic circulation of the South Pacific Ocean: flow patterns, tracers and transports. Progress in Oceanography 16, 1-62.

Reid, J.L., 1997. On the total geostrophic circulation of the Pacific Ocean: flow patterns, tracers and transports. Progress in Oceanography 39, 263-352.

Roether, W., Schlitzer, R., Putzka, A., Beining, P., Bulsiewicz, K., Rohardt, G., Delahoyde, F., 1993. A chlorofluoromethane and hydrographic section across Drake Passage: deep water ventilation and meridional property transport. Journal of Geophysical Research 98, 14423-14435.

Roether, W., Well, R., Putzka, A., Rüth, C., 1998. Component separation of oceanic helium. Journal of Geophysical Research 103, 27931-27946.

Roether, W., Well, R., Putzka, A., Rüth, C., 2001. Correction to "Component separation of oceanic helium". Journal of Geophysical Research 106, 4679.

Rüth, C., 1998. Heliumisotopen- und Neon-Messungen im Südatlantik: ozeanographische und geochemische Anwendungen. Doctoral Dissertation, Institut für Umweltphysik, University of Bremen, 1998, 117pp.

Rüth, C., Well, R., Roether, W., 2000. Primordial ${ }^{3}$ He in South Atlantic deep waters from sources on the Mid-Atlantic Ridge. Deep-Sea Research I 47, 1059-1075.

Schmitz, W.J., 1996. On the World Ocean Circulation, Vol. II: The Pacific and Indian Oceans/A Global Update. Woods Hole Oceanographic Institution, Technical Report WHOI96-08, 237pp.

Shaffer, G., Salinas, S., Pizarro, O., Vegas, A., Horzabal, S., 1995. Currents in the deep ocean off Chile $\left(30^{\circ} \mathrm{S}\right)$. Deep-Sea Research I 42, 425-436. 
Shaffer, G., Leth, O., Ulloa, O., Bendtsen, J., Daneri, G., Dellarossa, V., Hormazabal, S., Sehlstedt, P.-I., 2000. Warming and circulation change in the eastern South Pacific Ocean. Geophysical Research Letters 27 (9), $1247-1250$.

Sievers, H.A., Nowlin Jr, W.D., 1984. The stratification and water masses at Drake Passage. Journal of Geophysical Research 89, 10489-10514.

Tomczak, M., Large, D.G.B., 1989. Optimum Multiparameter Analysis of mixing in the thermocline of the Eastern Indian Ocean. Journal of Geophysical Research 94, 16141-16149.

Tsimplis, M.N., Bacon, S., Bryden, H.L., 1998. The circulation of the subtropical South Pacific derived from hydrographic data. Journal of Geophysical Research 103 (10), 21443-21468.
Tsuchiya, M., Talley, L.D., 1998. A Pacific hydrographic section at $88^{\circ} \mathrm{W}$ : water-property distribution. Journal of Geophysical Research 103, 12899-12918.

Warren, B.A., 1973. Transpacific hydrographic sections at Lats. $43^{\circ} \mathrm{S}$ and $28^{\circ} \mathrm{S}$ : the SCORPIO Expedition-II. Deep water. Deep-Sea Research 20, 9-38.

WCRP (World Climate Research Programme), 1988. World Ocean Circulation Experiment Implementation Plan, Vol. I: Detailed Requirements. World Meteorological Organisation, WMO/TD-No. 242, WCRP-No. 11.

Weiss, R.F., 1971. Solubility of helium and neon in water and seewater. Journal of Chemical Engineering Data 16, 235-241.

Well, R., Lupton, J., Roether, W., 2001. Crustal helium in deep Pacific waters. Journal of Geophysical Research 106, 14165-14177. 